\title{
The Utilization Of Cocopeat As Environmentally Friendly Composite
}

\author{
E.Y. Setyawan ${ }^{1,}$ S. Djiwo ${ }^{2}$, D.H Praswanto ${ }^{3}$, T.N. Prihatmi ${ }^{4},{ }^{5}$ D.Hermawan \\ 1,2,3,4 Department of Mechanical Engineering, National Institute of Technology Malang \\ ${ }^{5}$ Department of Mechanical Engineering, Widyagama University Malang \\ Correspondence: yohanes@lecturer.itn.ac.id
}

\begin{abstract}
The purpose of this study was to find environmentally friendly-based composite materials by utilizing natural materials that have been underutilized. The environmentally friendly composite is biodegradable which means that if it is not used it can decompose and will not affect or damage the environment. Not all natural ingredients are environmentally friendly; this depends on the application of the material. Composites made from cocopeat utilization can be applied to broad technical requirements. The maximum composite tensile strength test results were 13,473 MPa obtained in composites with 60\% matrix with 40\% coconut powder, shape and size using ASTM D638-3 and average impact strength $0,00994 \mathrm{~J} / \mathrm{mm}^{2}$ obtained from composite $60 \%$ matrix with coconut powder $40 \%$ the shape and size using ASTM D790-3, the process of using hand lay up. Adding a polyester matrix to the composite can increase the mechanical strength of the composite. On the other hand, excessive coconut powder in the mass fraction composite will reduce its mechanical strength. The observation of SEM photos in coconut powder shows the pores that can be used further to tie more matrices and able to increase the mechanical strength of the coconut powder composite.
\end{abstract}

Keywords: Cocopeat, Polyester, SEM, Impact Test and Tensile Test

Paper type Research paper

\section{INTRODUCTION}

The use of metal materials in various product components has diminished. This is due to the weight of components made of metal, the process of its formation which is relatively difficult, corrosive, and expensive at the cost of the production. Therefore, many other materials with similar characteristics of the desired metal material were developed, such as stainless steel have a tensile strength of $2.4 \mathrm{GN} / \mathrm{m}^{2}$ and a young modulus of $200 \mathrm{GN} / \mathrm{m}^{2}$ [6]. One material that is widely developed today is composite.

Composite is a material formed from a combination of two or more materials which have stronger mechanical properties than their forming materials. Composite consists of two parts, the matrix as a composite or protective binder as a composite filler. Natural fiber is alternative filler composite for various polymer composites because of its superiority over synthetic fibers. Natural fibers are easily obtained at a cheap price, easy to process, low density, environmentally friendly, and can be described biologically [7].

Composites have many functions in daily life include household needs and large industrial needs. By learning these composites, composite industry can be produced with more appropriate processes and materials; therefore they will have better value of strength and selling points.

Nowadays, the development of composite materials grows rapidly. Book written by Amar K. Mohaty explained that by far the use of composites was wide in the automotive sector. At present the composite also uses natural fibers as fiber and polyester as matrices. This is done because the strength of natural fibers is very good. Process of making composites using natural fibers can also be referred to as bio composite.

Composite materials are expected to be used as materials that have mechanical properties similar to and even better than metal, as a solution to prove that the material of the composite is capable of having maximum mechanical properties. The composite material has become one of the alternative materials used in household appliances, medical equipment, pharmaceutical equipment, and the world of transportation, as well as military equipment and aircraft. There have been many studies on composites that have been carried out and there are still many other untapped natural ingredients. Therefore this study will use a composite material from coconut fiber cork (cocopeat) that has never been done in a composite study.

Cocopeat is a waste from taking coconut fiber which has not been utilized optimally. In Indonesia, coconuts can be produced in an average of 15.5 billion annually. From this result, according to [3], about 1.8 million tons of fiber and 3.3 million tons of cocopeat can be produced. The availability of raw materials for cocopeat should be used to produce various economic and environmentally friendly products. The cocopeat has begun to be used as a planting medium by farmers, but it is still not widely used. In this study cocopeat is used as a composite that has the ability of mechanical properties to be applied in technical materials in the future. 


\section{METHOD}

\section{Research Material}

Cocopeat is obtained after the fibers are separated. Cocopeat is a coconut husk which is processed into cork granules, also known as Cocopeat. Polyester resin has a low price, easy to use and versatility. In addition, polyester has impact resistance, is resistant to all weather, transparent and has good surface effects. The disadvantage of using polyester resins is that they have less adhesion and inhibition properties than air and fillers.

\section{Composite Manufacture}

The cocopeat raw material is pre-treated, washed with an alkaline solution of $5 \% \mathrm{NaOH}$ and washed with distilled water until the acidity $(\mathrm{pH})$ shows number 7. The powder is dried and dried in an open room followed by drying oven according to ASTM D629 standard Qualitative Analysis of Textile Materials to obtain regain moisture and moisture content. The results of the initial treatment of cocopeat in the next stage are prepared for the process of making composites in accordance with tensile test specimens. The form of the specimen adjusts to the dimensions of the specimen to be made, referring to the ASTM D638 Type III standard and the impact of the shape and size using ASTM D790-3.

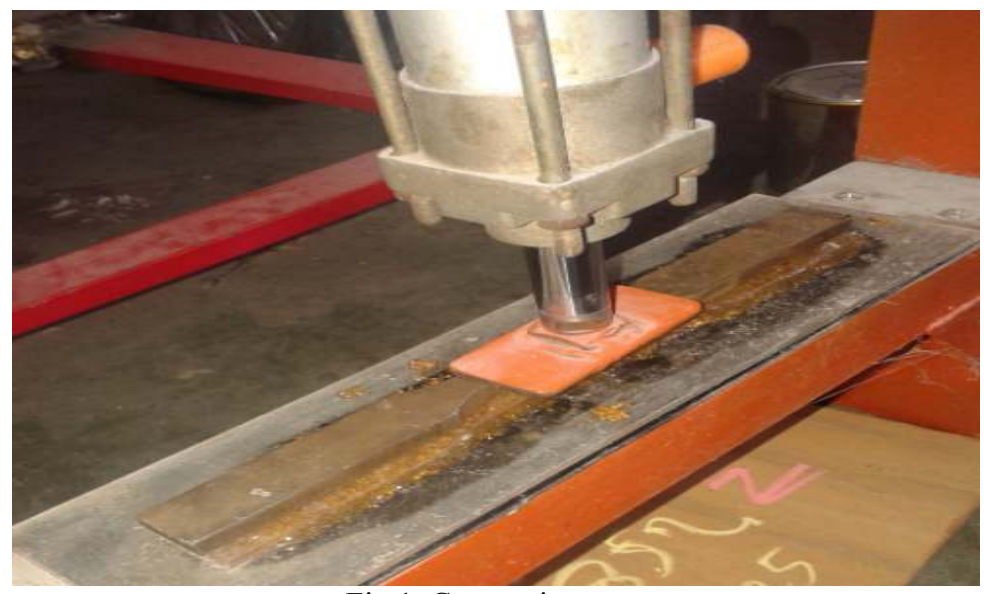

Fig 1. Composite press

The process of composite fabrication with hand lay-up process used hydraulic presses with a pressure of 150 Psi for 2 hours, with the help of air from the compressor with an outside air temperature of about $280 \mathrm{C}$. Each number of specimens was made 3 pieces.

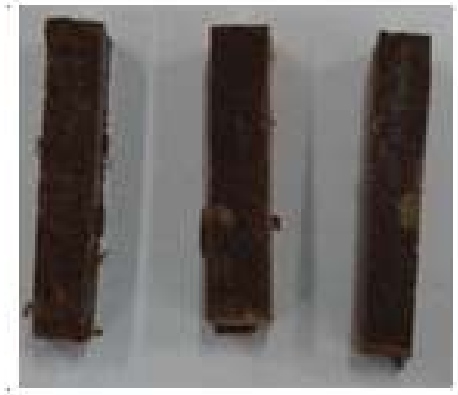

a)

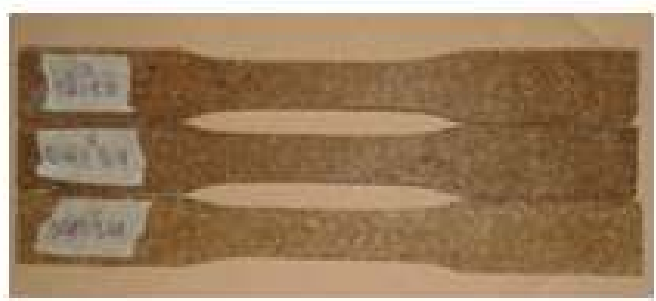

b)

Fig 2. a) Composite and b) impact test speciment

\section{Photo Observation}

Macro photos were carried out to determine differences in specimen surface conditions due to faults and the manufacturing process using the hand lay-up method. SEM photos were used to analyze the composite morphology of coconut powder with polyester matrix after testing was done to sess faults appeared. 


\section{DISCUSSION}

In this study, the manufacture of composite powder specimens from coconut waste using polyester matrix and hand layup method. This method is suitable as it is simple, easy and cheap. But on the other hand, this method also lacks because everything is done manually, not yet fully measured, therefore requires special expertise in making composite specimens. The example is shown in Figure. 3.

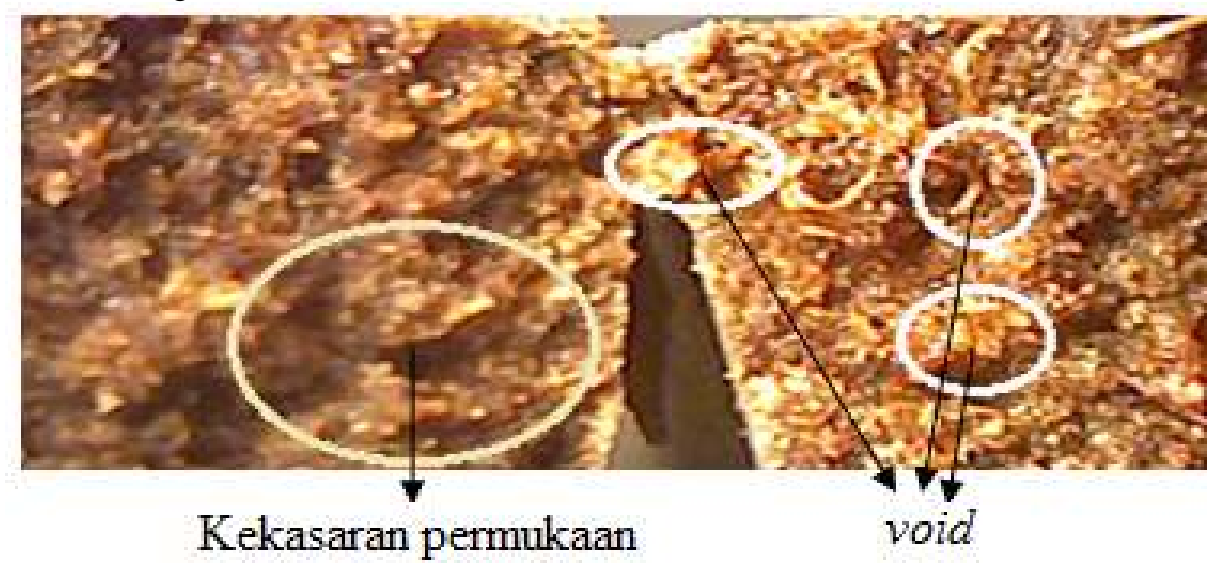

Fig 3. Macro Composite Photo of Coconut Powder with Polyester Matrix

In the process of manufacturing composite specimens, the unresolved difficulty is removing air trapped in composite specimens and composite surfaces that are not able to flat because the composite material is less moldable. It turns out that the hand lay-up method does not adequately handle the problem as shown in Figure 1. of voids and uneven surfaces. On the other hand coconut powder is included in a hydrophilic regime that is capable of dragging or humidity in the air so that there are voids in composition specimens that can affect the strength possessed by composites.

\section{Tensile strength}

Tensile strength is one of the basic properties of the material. The stress-strain relationship in the pull gives a fairly changing value depending on the rate of voltage, temperature, humidity. This is due to viscoelastic properties in polymeric materials. In thermoplastic materials such behavior is greatly changed by rectifying the chain molecules in the material. Generally the tensile strength of the polymer material is lower than other materials. Table 1 . Shows the results of tensile strength testing on composite specimens with mass fractions of coconut powder with polyester matrix using Alkali treatment of $5 \%$. Figure 4. shows a graph of the relationship between variations in mass fraction of coconut powder and polyester matrix.

Table 1. Tensile strength

\begin{tabular}{|c|c|c|c|}
\hline Area & Max Force & Tensile Strength & Specimen \\
\hline $\mathrm{mm}$ & $\mathrm{N}$ & $\mathrm{MPa}$ & Matrix (\%) \\
\hline 120 & 730 & 6,08 & 40 \\
\hline 120 & 570 & 4,75 & 40 \\
\hline 120 & 730 & 6,08 & 40 \\
\hline \multicolumn{2}{|c|}{ Average } & 5,64 & \\
\hline 120 & 860 & 7,17 & 50 \\
\hline 120 & 600 & 5 & 50 \\
\hline 120 & 600 & 5 & 50 \\
\hline \multicolumn{2}{|c|}{ Average } & 5,72 & \\
\hline 120 & 1480 & 12,33 & 60 \\
\hline 120 & 1890 & 15,75 & 60 \\
\hline 120 & 1480 & 12,33 & 60 \\
\hline \multicolumn{2}{|c|}{ Average } & 13,47 & \\
\hline
\end{tabular}




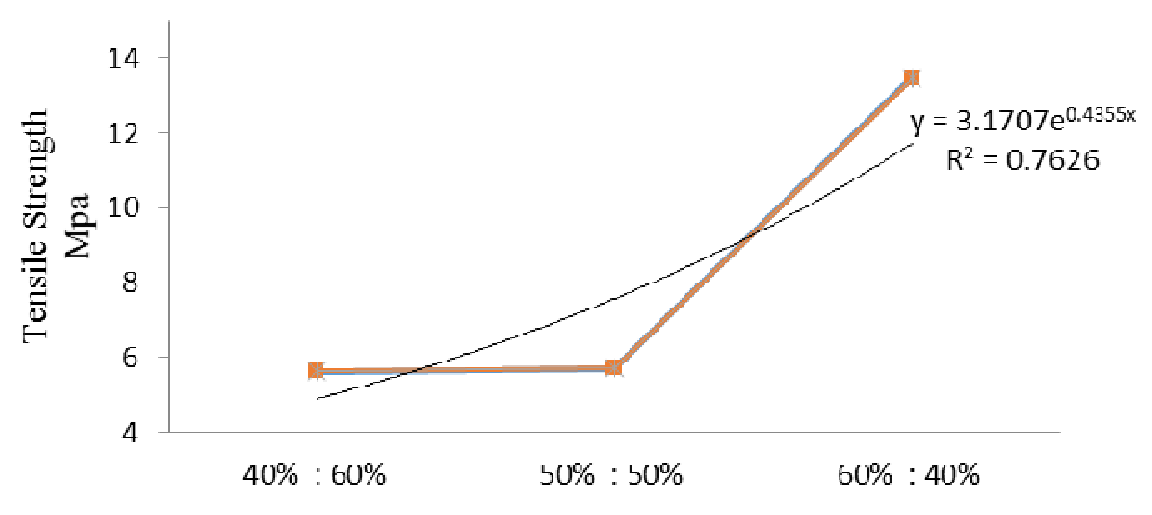

Komposisi Matrik : Serat (\%)

Fig 4. Composite Tensile Test Chart

Variations in polyester matrix mass fractions range from 40.50 and $60 \%$ then the tensile strength of composites using coconut powder is increasing. As shown in Figure 4. the more mass fraction of tensile strength increases and if the variation of mass fraction with coconut powder 40,50 and 60\% will have a downward trend. To find out the cause of this composite behavior, the fracture of the tensile test results was observed and it can be seen that for specimens with fiber mass fractions ranging from 40,50 and $60 \%$, the fibers of coconut powder are widely spread evenly throughout the fault cross section. However, for composite specimens with mass fractions that have more polyester matrices, they will have the trend of binding strength to the composite.

In the cross section of the fault, there are groups or clusters of fibers that have not been spread evenly and there are many voids so that the bonds between fibers and matrices do not occur and cause spaces between fibers with weak bonds. In this condition, when the tensile load occurs while testing the tensile strength, this well-bound fiber cluster area will separate first then become a concentration of stress and trigger cracks in the composite dominated by coconut powder, therefore the tensile strength begins to decrease to composite specimens with more mass fraction of coconut.

The results of this test show that in fact, the composite manufacturing process in this study was less than optimal as seen in the composite tensile test of coconut powder with a polyester matrix.

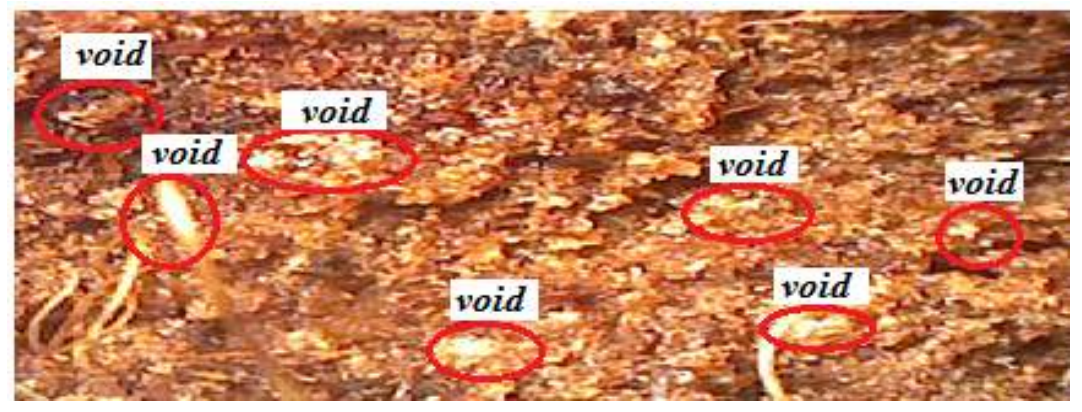

Fig 5. Fault of the Tensile Fraction Test Specimen of Cocopeat Mass

Polyester composites with maximum tensile strength in mass fractions with a $60 \%$ matrix. Therefore, it is necessary to do a more in-depth study to be able to increase the tensile strength of the mass fraction greater than $60 \%$. Besides, it can also be seen that composite tensile strength is the result of interaction between fiber and matrix during the manufacturing process. When making composites, the fibers can be spread evenly and bound by the matrix so that the maximum tensile strength will be obtained. But if during the manufacturing process the fiber cannot be dispersed and evenly bound by the matrix, a better tensile strength will be difficult to be obtained.

In the Rule of Mixture law to predict the strength of composites theoretically it can only apply if the fibers in the composite are scattered and bound evenly by the matrix. If there is a group of fibers that are not spread, the Rule of Mixture for short fiber composites cannot predict composite strength well. 


\section{Impact Strength}

Impact testing is carried out to determine the toughness of a material against shock loading. Impact is expressed as kinetic energy needed to initiate cracks and carry on until the material is completely deformed marked by breaking or breaking the composite specimen.

Table 2. Impact Test Data

\begin{tabular}{|c|c|c|c|c|c|c|c|c|c|}
\hline Beta & Alpha & Cos Beta & $\begin{array}{c}\text { Cos } \\
\text { Alpha }\end{array}$ & $\begin{array}{c}\mathrm{W} \\
(\mathrm{Kg})\end{array}$ & $\begin{array}{c}\mathrm{R} \\
(\mathrm{m})\end{array}$ & $\begin{array}{c}\mathrm{A} \\
(\mathrm{mm} 2)\end{array}$ & E (Joule) & HI (Joule $/ \mathrm{mm}^{2}$ ) & $\begin{array}{c}\text { Fiber } \\
(\%)\end{array}$ \\
\hline 25 & 30 & 0,91 & 0,86 & 26,32 & 0,65 & 80 & 0,851452 & 0,010643 & 40 \\
\hline 25,5 & 30 & 0,9 & 0,86 & 26,32 & 0,65 & 80 & 0,681162 & 0,008515 & 40 \\
\hline \multirow[t]{2}{*}{25} & 30 & 0,91 & 0,86 & 26,32 & 0,65 & 80 & 0,851452 & 0,010643 & 40 \\
\hline & & & Average & & & & 0,794689 & 0,009934 & \\
\hline 27,5 & 30 & 0,88 & 0,86 & 26,32 & 0,65 & 80 & 0,340581 & 0,004257 & 50 \\
\hline 27 & 30 & 0,89 & 0,86 & 26,32 & 0,65 & 80 & 0,510871 & 0,006386 & 50 \\
\hline \multirow[t]{2}{*}{27,5} & 30 & 0,88 & 0,86 & 26,32 & 0,65 & 80 & 0,340581 & 0,004257 & 50 \\
\hline & & & Average & & & & 0,397344 & 0,004967 & \\
\hline 29 & 30 & 0,87 & 0,86 & 26,32 & 0,65 & 80 & 0,17029 & 0,002129 & 60 \\
\hline 29 & 30 & 0,87 & 0,86 & 26,32 & 0,65 & 80 & 0,17029 & 0,002129 & 60 \\
\hline \multirow[t]{2}{*}{29} & 30 & 0,87 & 0,86 & 26,32 & 0,65 & 80 & 0,17029 & 0,002129 & 60 \\
\hline & & & Average & & & & 0,17029 & 0,002129 & \\
\hline
\end{tabular}

From the impact testing result shown in Table 2, the results of the toughness of the composite material of coconut powder with polyester matrix with the highest value is $0.002129 \mathrm{~J} / \mathrm{mm}^{2}$ with a composition of $40 \%$ coconut powder and $60 \%$ matrix. This occurs because the addition of matrices which are more dominant in composite specimens are able to distribute shock loads evenly throughout the composite section to inhibit the rate of fracture propagation due to impact loads, therefore the impact resistance will be greater.

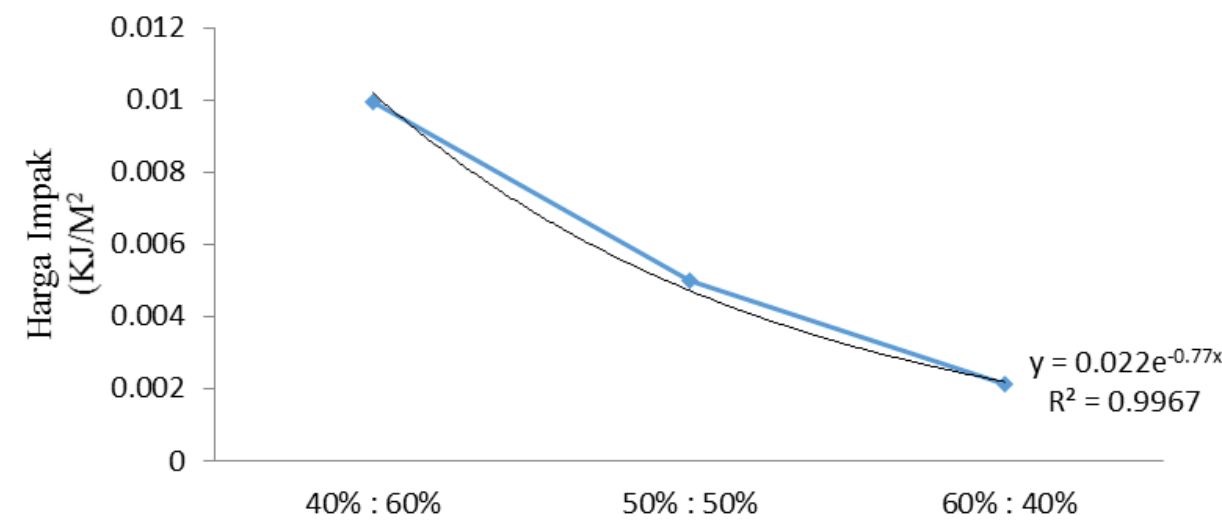

Komposisi Serat : Matrik (\%)

Fig 6. Composite Impact Price Chart

In Figure 6, it is shown that the composite impact strength with alkali treatment is known to increase the strength possessed by the composite. The strength of composite impact with reinforcement of coconut powder which is given alkali is higher than the composite impact strength with reinforcement of coconut powder which is without alkali because the mechanical bond that occurs between the matrix and coconut powder given alkali is stronger than the mechanical bond that occurs between the matrix and coconut powder without being given alkali.

Adding alkali to coconut powder can improve the properties of the coconut powder fibers. Alkali cleanses the surface walls of coconut powder from wax-like layers such as lignin, hemicellulose and other impurities that are still attached to the coconut powder which covers the pores owned by coconut powder which can later be filled with polyester matrices. Therefore it can increase strength due to the well bound as shown in Figure 7. SEM photos. 


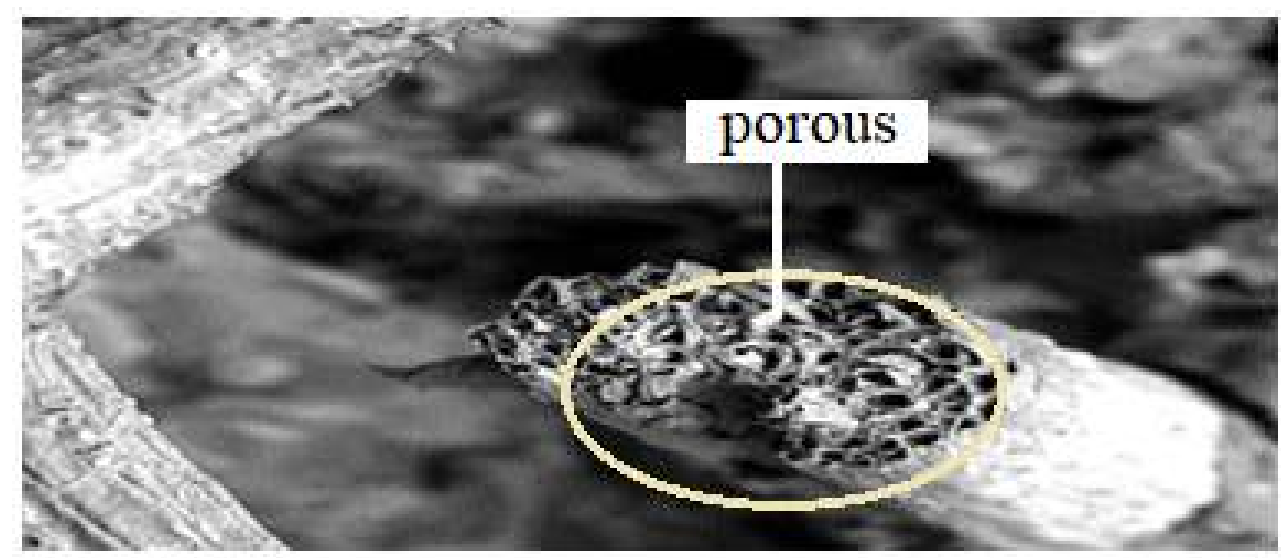

Fig 7. Composite SEM Photo

The morphology of coconut powder in the picture causes the surface wall of coconut powder to be coarser, until it appears porous or many holes found in coconut powder as can be seen in Figure 7. With the roughening surface of coconut powder and the loss of wax-like layers on the powder surface, the mechanical bond between the matrix and coconut powder will be stronger and more perfect because it is not blocked by the wax-like layer. Therefore, composite impact strength is increasing.

In addition, when the fiber is given an alkaline treatment ( $\mathrm{NaOH}$ solution), the $\mathrm{H}$ element that binds to coconut powder will react with $\mathrm{NaOH}$ and the $\mathrm{H}$ element will be replaced by the $\mathrm{Na}$ element. With this condition, the fiber walls will be difficult to react with water. With the limited fiber that reacts with water, the mechanical bond between the matrix and coconut powder will become stronger. With the advantages of coconut powder of having porous morphology, if an alkaline process is carried out it will open the pores in the coconut powder.

\section{CONCLUSION}

Addition of polyester matrices to composites can increase composite mechanical strength. However, if too much coconut powder in the composite mass fraction will reduce its mechanical strength. The strength of the composite composite maximum is $13,473 \mathrm{MPa}$ obtained in composites with $60 \%$ matrix and strength impact average $0,00994 \mathrm{~J} / \mathrm{mm}^{2}$ obtained from composite $60 \%$ matrix. From the morphology of coconut powder there are many pores available that can be used to fill more matrices to increase the mechanical strength of the composite.

\section{ACKNOWLEDGMENT}

This research was funded by the Internal Research Grant from the National Institute of Technology in Malang..

\section{REFERENCES}

[1] ASTM D629 Qualitative Analysis of Textile Materials

[2] ASTMD638,2005, Standard Test Methode for Tensile Properties of Plastics, American Society for Testing Materials, Philadelphia, PA.

[3] Arbintarso E. S., 2009, Tinjauan Kekuatan Lengkung Papan Serat Sabut Kelapa Sebagai Bahan Teknik, J. Teknologi, 2, 53-60.

[4] Gerges. S.N.Y. Muffler Modeling by Transfer Matrix Method and Experimental Verification, April 2006.

[5] Gosavi.Sanjay.S , Juge Vinayak .M. Nadgouda .Mayur.M. Optimization Of Suction Muffler using Taghuchi's DOE Method . International Compressor Engineering Conference at Purdue, July 17-20, 2006.

[6] Hardoyo,K.,2008, Karakterisasi Sifat Mekanis Komposit Partikel SiO2 dengan Matrik Resin Polyester, Tesis FMIPA, Program Studi Ilmu Material, UI

[7] Kusumastuti,A.,2009, Aplikasi Serat Sisal sebagai Komposit Polimer, Jurusan Teknologi Jasa dan Produksi, Universitas Negeri Semarang, Jurnal Kompetensi Teknik Vol.1, No.1, November 200927.

[8] Muller,D.H., Krobjilowski, A., 2003, New Discovery in the Properties of Composite Reinforced with Natural Fibers, Journal of Industrial Textiles, vol.33, no.2, pp.111-130 Sage Publ.

[9] Marsyahyo, E., Soekrisno, Rochardjo, H.S.B., Jamasri.,2006, Investigation of Chemical Surface Treatment of Ramie Fiber on Surface Morphology, Tensile Strength and Single Fiber Fracture Modes, International Seminar on Product Design and Development 2006, 13-14 December 2006, Gadjah Mada University, Yogyakarta.

[10] Mohanty, A.K. (2007). Biobased Material for Sustainable Future, Ontario Bioauto Council Annual Seminar, 25 September 2007. 
[11] E. Setyawan and H. Ambarita, "A Preliminary Field Test of a Natural Vacuum Solar Desalination Unit Using Hybrid Solar Collector," in AIP Conference Proceedings, (2018) 020014.

[12] E. Y. Setyawan F. H. Napitupulu and H Ambarita "Study on the Characteristics of a Natural Vacuum Desalination System Using Solar Energy as Energy Sources,” Int. J. Mech. Mechatronics Eng., (2018) vol. 18, no. 05,.

[13] E.Y. Setyawan, R.A.M. Napitupulu, P. Siagian , H Ambarita, Field tests of a natural vacuum solar desalination system using hybrid solar collector, IOP Conf. Series: Materials Science and Engineering 237, (2017) 012012.

[14] E.Y Setyawan, S Djiwo and T Sugiarto, Simulation Model of Fluid Flow and Temperature Distribution in Porous Media Using Cylinder Convergent and Divergent Nozzle, Internasional Journal of Technology and Sciences, 1 (2017) 1-10. 